\title{
Antibiotic resistance patterns of pathogenic Gram negative bacteria isolated from UTI patients in Sirajganj district
}

\author{
Fouzia Ferdows Khan Chowdhury ${ }^{1}$, Sunjukta Ahsan ${ }^{2}$ and Md. Shahidul Kabir ${ }^{1 \neq}$ \\ ${ }^{1}$ Department of Microbiology, Stamford University Bangladesh, 51 Siddeswari Road, Dhaka 1217, \\ Bangladesh; ${ }^{2}$ Department of Microbiology, University of Dhaka, Dhaka 1000, Bangladesh
}

Received 28 April 2013/Accepted 10 June 2013

\begin{abstract}
Urinary tract infection (UTI) is a common cause of illness in people of all age groups. The increasing trend of antibiotic resistance is now a concern worldwide. The present study was conducted to determine the antibiotic resistance pattern of Gram negative pathogenic isolated from UTI cases in Sirajganj district. A total of 297 uropathogens were included in this study of which $66(22.2 \%)$ were isolated from male patients and $231(\mathbf{7 7 . 8 \%})$ from female patients. Escherichia coli $(\mathbf{5 2 . 9 \%})$ was found to be the predominant pathogen followed by Klebsiella spp. (22.9\%), Proteus spp. (4.7\%), Psudomonas spp. (4.4\%), Enterobacter spp. (2.4\%), Citrobacter spp. (3\%) and Morganella spp. (5.7\%). Most of the uropathogens were resistant against Ampicillin (AMP). Meropenem was the most effective antibiotic with resistance between 0 and $15.1 \%$ of the tested isolates. However, the trend of antibiotic resistance can vary with the change in the environmental and socioeconomic conditions. Accurate diagnosis of UTI and determination of antibiotic sensitivity pattern is important for selection of appropriate drug for effective treatment.
\end{abstract}

Key words: UTI; Antibiotic resistance; Pathogens; Gram negative bacteria

Urinary Tract Infection (UTI) is a broad term used to describe a group of diseases resulting from the microbial colonization of the urinary tract (1). It may affect the upper (pyelonephritis) or lower (cystitis) urinary tract. It is one of the most common bacterial illnesses which incur health care expenditures in the general population (1). Both Gram positive and negative bacteria can cause UTI upon entering the urinary tract at levels more than or equal to $10^{5}$ colony forming units of bacteria/ml of urine. The predominant members of bacterial pathogens belong to the family Enterobacteriaceae (2). UTIs can occur in individual patient or may be acquired from hospitals (3).

According to previous reports, approximately 150 million individuals are affected annually worldwide (4). An increase in antibiotic resistance in pathogenic bacteria is now a prime concern worldwide. Likewise, increasing trend of antimicrobial resistance in uropathogens has complicated the empirical therapy leading to treatment failures (5-7). This study was aimed to determine the antibiotic resistance patterns of Gram-negative bacteria isolated form UTI patients in Sirajganj district

\section{MATERIALS AND METHODS}

Study area, sampling and sample processing. This study was carried out in

${ }^{*}$ Corresponding Author: Mailing address. Dr. Md. Shahidul Kabir, Department of Microbiology, Stamford University Bangladesh, 51 Siddeswari Road, Dhaka 1217, Bangladesh; E-mail: mskabir@yahoo.com. the Microbiology laboratory of Avicenna Hospital Ltd., Sirajganj, Bangladesh. Urine samples of both hospitalized and outdoor patients from June 2012 to May 2013 were used for the investigation. Clean catch mid-stream urine samples were collected in sterile containers for microbiological analysis.

Urine culture. Urine samples $(10 \mu \mathrm{l})$ were streaked on to MacConkey agar (Oxoid, UK) and Nutrient agar (Oxoid, UK) media and incubated aerobically at 37 ${ }^{\circ} \mathrm{C}$ for 24 hours for isolation and identification of pathogenic bacteria. Samples with colony counts on Nutrient agar of $\geq 1 \times 10^{5} \mathrm{cfu} / \mathrm{ml}$ were considered as positive for the presence of pathogens. Corresponding bacterial colonies on MacConkey agar were further identified to determine the type of pathogen.

Identification of bacterial isolates. Bacteria present in the positive urine samples were biochemically identified following standard methods. Clinical isolates were characterized by microscopic examination (Gram staining), oxidase test, motility, citrate utilization and Triple Sugar Iron utilization tests for species identification. The uropathogen Pseudomonas aeruginosa was also identified by production of diffusible pigments on Mueller-Hinton Agar.

Antibiotic susceptibility assay of bacterial isolates. Antimicrobial susceptibility testing of the bacterial isolates was performed by the disk diffusion method (8) in accordance with the Clinical \& Laboratory Standards Institute guideline (9). Quality controls employed standard strains of E. coli ATCC 25922. Antibiotics included in this study include: Amoxy-Clavulanic acid (Aclav, $3 \mu \mathrm{g}$ ),

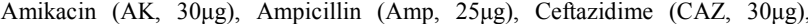

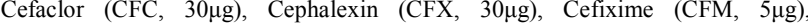

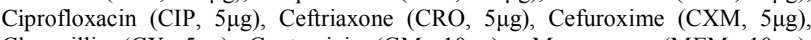

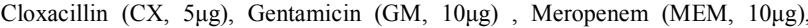

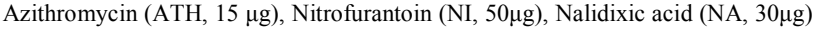
and Tobramycin (TOB, $30 \mu \mathrm{g}$ )

\section{RESULTS}

A total of 297 uropathogens were investigated in this study. Of the 297 pathogens, $66(22.2 \%)$ were isolated from male patients and $231(77.8 \%)$ from female patients. The proportions of pathogenic bacteria isolated from UTI patients are shown in Table 1. E. coli was the predominant uropathogen $(52.9 \%)$ causing UTI followed by Klebsiella pneumonia $(22.9 \%)$ and Proteus mirabilis (4.7\%).

Table 2 shows proportions of resistant bacteria against 
TABLE 1. Frequency of bacteria isolate for UTI patent

\begin{tabular}{ccc}
\hline Bacteria & No. of isolates & Frequency (\%) \\
\hline Escherichia coli & 159 & 52.9 \\
Klebsiella $\mathrm{spp}$ & 73 & 22.9 \\
Proteus $\mathrm{spp}$ & 14 & 4.7 \\
Pseudomonas $\mathrm{spp}$ & 17 & 4.4 \\
Enterobacter $\mathrm{spp}$ & 7 & 2.4 \\
Citrobacter $\mathrm{spp}$ & 9 & 3.0 \\
Morganella morganelli & 18 & 5.7 \\
\hline
\end{tabular}

17 types of antibiotics. E. coli showed highest resistance Nalidixic acid (NA) (36.5\%) and lowest against Meropenem. The majority of Klebsiella spp. was resistant against Cephalexin, CFX (4.7\%) and less resistance against Nitrofurantoin, NI (4.1\%). Proteus spp. were mostly resistant against Cloxacillin, CX (48.9\%) followed by against Amoxycillin-clavulanic (Aclav) acid (35.7\%) and cefixime, CFM (35.7\%).They were sensitive against Meropenem (MEM) and Nitrofurientoin (NI). Enterobacter spp. was equally resistant (28.6\%) against the antibiotics Aclav, CFX, CFM, Ciprofloxacin (CIP) and Tobramycin (TOB). They were completely sensitive to a number of antibiotics including AK, CAZ and MEM. Majority of the Citrobacter spp. showed resistance against Cefuroxime, CXM (55.6\%) and were sensitive to MEM, NA and TBO. In contrast, significantly higher percentages of Morganella morganelli and Pseudomonas spp. showed resistance to the antibiotics investigated. A total of $72.2 \%$ Morgenalla morganelli showed resistance against Ampicillin followed by $66.66 \%$ of the isolates showing resistance against Aclav. In contrast, Morganella spp. was sensitive to
AK. Psedomonas spp. demonstrated highest level of resistance against Aclav (71.42\%) and showed sensitivity to CAZ and NI.

The majority of the uropathogens (Morganella morganelli, Pseudomonas spp., Proteus spp. and Enterobacter spp.) were resistant against Aclav. Two of the uropathogens (Klebsiella spp. and Enterobacter spp.) showed maximum resistance against CFX and two others, E. coli and Klebsiella spp., against NA. A maximum of four pathogenic genera (E. coli, Proteus, Enterobacter and Citrobacter) were fully sensitive to MEM, three genera (Pseudomonas, Proteus and Citrobacter) to NI, two genera (Morganella morganelli and Enterobacter) to $\mathrm{AK}$ and two genera (Pseudomonas and Enterobacter) to CAZ.

\section{DISCUSSION}

The prevalence of UTIs is high in Bangladesh and other developing countries, affecting individuals in the community of different age groups of both sexes (10). Urinary tract infection results as a consequence of entry and colonization of pathogenic bacteria in the urinary system. This study focuses on the antibiotic resistance patterns of the Gram negative bacteria isolated from UTI patients in Sirajganj district of Bangladesh. It may be worth to mention that most of the previous reports on UTI in Bangladesh are either from Dhaka or Chittagong city. This is possibly due to the limited laboratory facilities outside these areas. This study was conducted at the Avicenna Hospital Ltd., Sirajganj and to our knowledge constitutes the first report of its kind from this area.

TABLE 2. Proportions of pathogenic bacteria exhibited resistance to 21 selected antibiotics

\begin{tabular}{|c|c|c|c|c|c|c|c|}
\hline $\begin{array}{l}\text { Antibiotic } \\
\text { Disc }\end{array}$ & $\begin{array}{l}\text { E. coli } \\
(\%)\end{array}$ & $\begin{array}{l}\text { Klebsiella } \\
\text { spp. }(\%)\end{array}$ & $\begin{array}{c}\text { Morganella } \\
\text { morganelli }(\%)\end{array}$ & $\begin{array}{c}\text { Pseudomonas } \\
\text { spp. }(\%)\end{array}$ & $\begin{array}{c}\text { Proteus spp. } \\
(\%)\end{array}$ & $\begin{array}{c}\text { Enterobacter } \\
\text { spp. }(\%)\end{array}$ & $\begin{array}{c}\text { Citrobacter } \\
\text { spp. }(\%)\end{array}$ \\
\hline Aclav & 24.5 & 16.4 & 66.7 & 58.8 & 35.7 & 28.6 & 22.2 \\
\hline AK & 3.1 & 8.2 & 0.0 & 27.8 & 7.1 & 0.0 & 11.1 \\
\hline $\mathrm{AmP}$ & 28.3 & 21.9 & 72.2 & 52.9 & 50.0 & 21.4 & 44.4 \\
\hline CAZ & 7.6 & 8.2 & 22.2 & 0.0 & 7.1 & 0.0 & 22.2 \\
\hline $\mathrm{CFC}$ & 27.0 & 16.4 & 44.4 & 23.5 & 7.1 & 21.4 & 33.3 \\
\hline CFX & 33.3 & 24.7 & 50.0 & 47.1 & 21.4 & 28.6 & 44.4 \\
\hline CFM & 23.3 & 17.8 & 33.3 & 23.5 & 35.7 & 28.6 & 22.2 \\
\hline CIP & 20.8 & 9.9 & 33.3 & 35.3 & 21.4 & 28.6 & 33.3 \\
\hline CRO & 17.2 & 19.2 & 38.9 & 17.6 & 28.6 & 21.4 & 11.1 \\
\hline CXM & 23.9 & 16.4 & 55.6 & 47.1 & 21.4 & 21.4 & 55.6 \\
\hline CX & 18.9 & 20.5 & 27.8 & 35.3 & 48.9 & 14.3 & 44.4 \\
\hline GM & 6.9 & 13.7 & 44.4 & 5.9 & 14.3 & 14.3 & 11.1 \\
\hline MEM & 0.0 & 15.1 & 1.4 & 11.8 & 0.0 & 0.0 & 0.0 \\
\hline ATH & 16.9 & 13.7 & 61.1 & 11.8 & 14.3 & 0.0 & 11.1 \\
\hline NI & 3.1 & 4.1 & 5.6 & 0.0 & 0.0 & 14.3 & 0.0 \\
\hline NA & 36.5 & 24.7 & 61.1 & 52.9 & 28.6 & 21.4 & 22.2 \\
\hline TOB & 4.4 & 6.8 & 11.1 & 17.6 & 7.1 & 28.6 & 0.0 \\
\hline
\end{tabular}

Aclav = Amoxy-Clavulanic acid $(3 \mu \mathrm{g}) ; \mathrm{AK}=$ Amikacin $(30 \mu \mathrm{g}) ; \mathrm{Amp}=$ Ampicillin $(25 \mu \mathrm{g}) ; \mathrm{CAZ}=\mathrm{Ceftazidime}(30 \mu \mathrm{g})$; CFC $=\mathrm{Cefaclor}(30 \mu \mathrm{g})$; $\mathrm{CFX}=$ Cephalexin $(30 \mu \mathrm{g}) ; \mathrm{CFM}=$ Cefixime $(5 \mu \mathrm{g})$; CIP = Ciprofloxacin $(5 \mu \mathrm{g})$; CRO= Ceftriaxone $(5 \mu \mathrm{g}) ; \mathrm{CXM}=\mathrm{Cefuroxime}(5 \mu \mathrm{g}) ; \mathrm{CX}=$ Cloxacillin $(5 \mu \mathrm{g}) ; \mathrm{GM}=$ Gentamicin $(10 \mu \mathrm{g}) ; \mathrm{MEM}=$ Meropenem $(10 \mu \mathrm{g}) ; \mathrm{ATH}=$ Azithromycin $(15 \mu \mathrm{g})$; NI = Nitrofurantoin $(50 \mu \mathrm{g})$; NA = Nalidixic acid $(30 \mu \mathrm{g}) ; \mathrm{TOB}=$ Tobramycin $(30)$. 
The antibiotic susceptibility pattern of the major uropathogens in all age groups from Sirajganj district demonstrates that a higher proportion of females $(n=231,77.8 \%)$ were infected than males $(n=66$, $22.2 \%$ ). Similar observations were made by other workers in studies with uropathogens from Bangladesh $(10,11)$. Several factors are reported to be associated with the development of UTIs viz. poor personal hygiene, pregnancy, urinary tract obstruction, urethral reflux, long term catheterization, sexual intercourse, spermicidal contraception and a history of UTIs (11, 12). It has been observed that a large portion of all women, up to one-third, experience UTI at some point during their lifetime which may be related to their anatomical structure of genitourinary system $(13,14)$. The notable features which are found to be associated with UTI are short urethra, proximity of the urethra to the anus and colonization of the vagina by members of the faecal flora that facilitate ascending infection into bladder (14).

Until recently, fluoroquinolones were preferred antibiotics prescribed for UTI patients because of their low rates of resistance, among most common uropathogens and high efficiency in curing patients (15, 16). They are available in both oral and intravenous formulations and easy for administration in different medical conditions. Fluoroquinolones are easily absorbed and rapidly excreted from the body under normal conditions $(15,17,18)$. However, the wide spread use of this broad spectrum antibiotics has provoked pathogens to acquire drug resistance in UTI patients (19-23). Continuous evolution of antibiotic resistance has emerged due to the indiscriminate use of antibiotics and not completing the antibiotics course properly. It is now necessary to reassess the antibiotic sensitivity patterns to determine the drug of choice for managing UTI $(20,24)$.

E. coli was the predominant organism causing UTIs in the majority of the screened patients. This is in concordance with other findings both from Bangladesh $(10,11)$ and overseas $(25,26)$. It has been observed in previous study that bacterial resistance emerges subsequent to the clinical use any antibiotic (27). Antibiotic resistance by pathogenic microorganisms was recognized as an increasing global problem and had become an important factor to be considered in the treatment of infections (25). In the present investigation, most of the predominant uropathogens were sensitive to Meropenem. Sensitivity of Morganella morganelli and Pseudomonas spp. was observed maximally to NI. This suggests that at the current antimicrobial sensitivity status of the uropathogens, Meropenem or NI is a better option for treatment over other antibiotics. As antibiotic resistance is an important factor, urine culture and antibiotic sensitivity tests should be routinely performed in all UTI cases. Appropriate antibiotics need to be prescribed based on the antibiotic susceptibility test which will be narrow spectrum, effective and less expensive with least side effects.

\section{REFERENCES}

1. Kunin, C. M. 1994. Urinary tract infections in females. Clin. Infect. Dis. 18 $1-12$

2. Neu, H. C. 1992. The crisis in antibiotic resistance. Science 257 (5073): $1064-$ 73.

3. Gupta, K., D. F. Sahm, D. Mayfield, and W. E. Stamm. 2001 Antimicrobial resistance among uropathogens that cause community acquired urinary tract infections in woman: a nationwide analysis. Clin. Infect. Dis. $\mathbf{3 3}$ 89-94.

4. Stamm, W. E. and S. R. Norby. 2001. Urinary tract infections: Disease panorama and challenges. J. Infect. Dis. 183: 1-4.

5. Naveen, R., and E. Mathai. 2005. Some virulence characteristics of uropathogenic Escherichia coli in different patient groups. Indian J. Med. Res. 122: $143-147$.

6. Karlowsky, J. A., et al. 2002. Trends in Antimicrobial resistance among urinary tract infection isolates of Escherichia coli from female outpatients in the United States. Antimicrob. Agents Chemother. 46 (8): 2540-2545.

7. Blondeau, J. M., and D. Vaughan. 2000. In vitro activity of 19 antimicrobial agents against 3513 nosocomial pathogens collected from 48 Canadian medical centres. Int. J. Antimicrob. Agents 15 (3): 213-219.

8. Bauer, A. W., W. M. M. Kirby, J. C. Sherris, and M. Turck. 1966 Antibiotic susceptibility testing by a standardized single disk method. Am. J. Clin. Pathol. 45 (4): 493- 496.

9. Clinical and Laboratory Standards Institute (CLSI). 2011. Performance Standards for Antimicrobial Susceptibility Testing; Twenty-First Informational Supplement. CLSI document M100-S21 (ISBN 1-56238-7421). Clinical and Laboratory Standards Institute, 940 West Valley Road, Suite 1400, Wayne, Pennsylvania 19087 USA.

10. Shahina, Z., et al. 2011. A Study of Antibacterial Susceptibility and Resistance Pattern of E. coli Causing Urinary Tract Infection in Chittagong, Bangladesh. Asian J. Biol. Sci. 4: 548-555.

11. Nahar, S. J., H. Khanum, and K. Shimasaki. 2010. Occurrence of Escherichia coli infection among the women of Dhaka city. ARPN J. Agric. Biol. Sci. 5: 68-73

12. Moges, A. F., A. Genetu, and G. Mengistu. 2002. Antibiotic sensitivities of common bacterial pathogens in urinary tract infections at Gondar Hospital, Ethiopia East Afr. Med. J. 79: 140-142.

13. Valiquette, L. 2001. Urinary tract infections in women. Can. J. Urol. 1: 6-12.

4. Levinson, W., and E. Jawetz, 2000. Medical microbiology and immunology: Examination and board review, $6^{\text {th }}$ ed. McGraw-Hill, New York.

15. Drago, L., et al. 2001. Activity of levofloxacin and ciprofloxacin against urinary pathogens. J. Antimicrob. Chemother. 48 (1): 37-45.

16. Schaeffer, A. J. 2002. The expanding role of fluoro- quinolones. Am. J. Med. 113: $45 \mathrm{~S}-54 \mathrm{~S}$

17. Kamberi, M., et al. 1999. Influences of urinary $\mathrm{pH}$ on ciprofloxacin pharmacokinetics in humans and antimicrobial activity in vitro versus those of sparfloxacin. Antimicrob. Agents Chemother. 43 (3): 525-529.

18. King, D. E., R. Malone, and S. H. Lilley. 2000. New classification and update on the quinolone antibiotics. Am. Fam. Physician 61 (9): 2741-2748.

19. Shao, H. F., W. P. Wang, X. W. Zhang, and Z. D. Li. 2003. Distribution and resistance trends of pathogens from urinary tract infections and impact on management. Zhonghua Nan. Ke. Xue. 9 (9):690-692.

20. Kahlmeter G. 2003. An international survey of the antimicrobial susceptibility of pathogens from uncomplicated urinary tract infections: the ECO.SENS Project J. Antimicrob. Chemother. 51 (1): 69-76.

21. Iqbal, J., M. Rahman, M. S. Kabir, and M. Rahman. 1997. Increasing ciprofloxacin resistance among prevalent urinary tract bacterial isolates in Bangladesh. Jpn. J. Med. Sci. Biol. 50 (6): 241-250.

22. Astal, Z., A. El-Manama, and F. A. Sharif. 2002. Antibiotic resistance of bacteria associated with community- acquired urinary tract infections in the southern area of the Gaza Strip. J. Chemother. 14 (3): 259- 264.

23. Astal, Z., F. A. Sharif, S. A. Abdallah, and M. I. Fahd. 2002. Multiresistant Escherichia coli isolated from women with community-acquired urinary tract infections in the Gaza Strip. J. Chemother. 14 (6): 637-638.

24. Miller, K., A. J. O'Neill, and I. Chopra. 2002. Response of Escherichia coli hypermutators to selection pressure with antimicrobial agents from different classes. J. Antimicrob. Chemother. 49 (6): 925-934.

25. Tamberkar, D. H., et al. 2006. Antibacterial susceptibility of some urinary a 
tract pathogens to commonly used antibiotics. Afr. J. Biotechnol. 5: 15621565 .

26. Jones, R. N., H. I. Inabo, and H. B. I. Obanibi. 2006. Antimicrobial susceptibility of some urinary tract clinical isolates to commonly used antibiotics. Afr. J. Biotechnol. 5 (5): 487-489
27. Raco, M. V. O., and M. Y. C. Barez. 1998. Profile of community-acquired urinary tract infection in Davao City, Philpp. J. Microbiol. Infect. Dis. 27: 6266 